\title{
Loss of soil microbial diversity exacerbates spread of antibiotic resistance
}

\author{
Qing-Lin Chen ${ }^{1}$, Xin-Li An ${ }^{1}$, Bang-Xiao Zheng ${ }^{1,2}$, Michael Gillings ${ }^{3}$, Josep Peñuelas ${ }^{4,5}$, Li Cui ${ }^{1}$, \\ Jian-Qiang Su${ }^{1}$, Yong-Guan $\mathrm{Zhu}^{1,6, *}$
}

1 Key Laboratory of Urban Environment and Health, Institute of Urban Environment, Chinese Academy of Sciences, Xiamen 361021, China 2 University of Chinese Academy of Sciences, 19A Yuquan Road, Beijing 100049, China

3 Department of Biological Sciences, Macquarie University, Sydney, NSW, 2109, Australia

4 Consejo Superior de Investigaciones Científicas (CSIC), Global Ecology Unit, Centre for Ecological Research and Forestry Applications

(CREAF)-CSIC- Universitat Autonoma de Barcelona (UAB), Bellaterra, 08193 Barcelona, Catalonia, Spain

5 CREAF, Cerdanyola del Vallès, 08193 Barcelona, Catalonia, Spain

6 State Key Laboratory of Urban and Regional Ecology, Research Center for Eco-Environmental Sciences, Chinese Academy of Sciences, Beijing 100085, China

\section{ARTICLE INFO}

\section{Article history:}

Received October 30, 2018

Revised November 5, 2018

Accepted November 10, 2018

\section{Keywords:}

Biodiversity

Biological barrier

Invasiveness

Ecosystem functioning

\section{A B S T R A C T}

Loss of biodiversity is a major threat to the ecosystem processes upon which society depends. Natural ecosystems differ in their resistance to invasion by alien species, and this resistance can depend on the diversity in the system. Little is known, however, about the barriers that microbial diversity provides against microbial invasion. The increasing prevalence of antibioticresistant bacteria is a serious threat to public health in the 21 st century. We explored the consequences of the reduction in soil microbial diversity for the dissemination of antibiotic resistance. The relationship between this diversity and the invasion of antibiotic resistance was investigated using a dilution-to-extinction approach coupled with high-capacity quantitative PCR. Microbial diversity was negatively correlated with the abundance of antibiotic-resistance genes, and this correlation was maintained after accounting for other potential drivers such as incubation time and microbial abundance. Our results demonstrate that high microbial diversity can act as a biological barrier resist the spread of antibiotic resistance. These results fill a critical gap in our understanding of the role of soil microbial diversity in the health of ecosystems.

(c) Higher Education Press 2019

\section{Introduction}

Biodiversity is fundamental to the maintenance of ecosystem functioning. Diverse species pools sustain healthy ecosystems by supporting multiple ecosystem functions and ser-

\footnotetext{
* Corresponding author

E-mail address: ygzhu@iue.ac.cn (Y.G. Zhu)
}

vices, including biogeochemical cycling, primary production, litter decomposition and climatic regulation (Wardle et al., 2004; van der Heijden et al., 2008; Bardgett and van der Putten, 2014; Wagg et al., 2014). Genomic techniques have identified immense microbial diversity in both soil and oceans (Torsvik et al., 1998; Torsvik and Ovreas, 2002; DeLong et al., 2006; Sogin et al., 2006), but the role of microbial diversity in controlling ecosystem function remains unclear (Hillebrand and Matthiessen, 2009; Peter et al., 2011; Miki et al., 2013). 
Anthropogenic activities such as agricultural intensification, altered land use and nitrogen enrichment might reduce microbial diversity and potentially affect ecosystem functions (Mäder et al., 2002; Gans et al., 2005; Maestre et al., 2015).

Debate continues about the relationship between microbial diversity and ecosystem functioning (Bell et al., 2005; Allison and Martiny, 2008). Soil microorganisms are key drivers of biogeochemical flows, but the functional redundancy in soil microorganisms suggests that some loss of microbial diversity might not substantially affect ecosystem functions (Bell et al., 2005; Wertz et al., 2006; Wertz et al., 2007), especially if the relationship between microbial diversity and ecosystem functioning is saturated (Cardinale et al., 2011; Reich et al., 2012). For example, communities of microbial decomposers are often highly redundant for a single function, such as microbial respiration or biomass production (Reinthaler et al., 2005; Reich et al., 2012). The relationship between biodiversity and function, however, might depend on the presence of key species, particularly if the function of concern is more specific and limited to a few taxa (such as pesticide degradation) (Gamfeldt et al., 2008; Obernosterer et al., 2010; Singh et al., 2014). The buffering capacity of ecosystems might be limited for specialized functions so that a moderate loss of diversity could substantially impair key processes (Singh et al., 2014). Relationships between microbial diversity and ecological functions may nevertheless involve trade-offs and may not necessarily be generalized as positive, neutral or negative (Jung et al., 2016). Investigating the consequences of loss in biodiversity for the process and functioning of ecosystems is thus of considerable interest (Swift et al., 1998; Chapin et al., 2000; Hunt and Wall, 2002; Loreau, 2004; Wardle et al., 2011; Perveen et al., 2014).

Highly biodiverse ecosystems are less vulnerable to disturbances (Elton, 1958; Levine, 2000; Ricciardi and Maclsaac, 2008) and can be resistant to invasion by alien species (Vitousek et al., 1996; Kennedy et al., 2002). Whether this principle can be applied to microbial ecology remains largely unresolved. The relationship between invasibility and microbial diversity has been investigated by manipulating microbial communities (van Elsas et al., 2007; Wertz et al., 2007; van Elsas et al., 2012; Philippot et al., 2013; Sun et al., 2015). Survival of inoculant Escherichia coli $\mathrm{O} 157: \mathrm{H} 7$ has been positively correlated with the depth of soil fumigation using a dilution-reinoculation approach, where soil microbial diversity was negatively correlated with survival of the invader (van Elsas et al., 2007; van Elsas et al., 2012; Vivant et al., 2013). Survival rate has been negatively correlated with the degree of microbial diversity for inoculation with Pseudomonas aeruginosa, Ralstonia solanacearum and Listeria monocytogenes (Matos et al., 2005; Irikiin et al., 2006; Vivant et al., 2013). Such data shed light on the relationship between complexity and invasiveness within microbial communities and are valuable but cannot be regarded as universal due to the limited number of species investigated.

Only a fraction of bacteria in natural environments can be cultivated, so we focused on the relationship between invasibility and microbial diversity at the gene level using the antibiotic resistome as a proxy for invasion (Wright, 2007). The emergence and spread of antibiotic resistance has become a global health threat (Bush et al., 2011; Pruden et al., 2013; Zhu et al., 2013; Su et al., 2017; Zhu et al., 2018), but the factors regulating the environmental dynamics of antibiotic resistance, especially biotic factors, have not been directly addressed. This neglect has hampered our ability to assess the risks of antibiotic resistance due to anthropogenic activities and global environmental change.

The main objective of this study was to determine if soil microbial diversity could act as a biological barrier to prevent the invasion of antibiotic resistance by addressing the consequences of a loss of soil microbial diversity on the fate of antibiotic-resistance genes (ARGs). Microbial diversity was manipulated using a dilution-reinoculation approach, and pig manure was used as the source of determinants of antibiotic resistance. We characterized bacterial communities using Illumina Hiseq profiles of $16 \mathrm{~S}$ rRNA genes and the resistome was determined using high-capacity quantitative PCR that targeted major classes of ARGs. Our study provides empirical evidence that high microbial diversity lowers the survival and dissemination of ARGs in soil ecosystems, suggesting that the loss of microbial diversity could exacerbate the spread of resistance.

\section{Materials and methods}

\subsection{Microcosms and experimental setup}

Surface soil $(0-20 \mathrm{~cm})$ was collected from a rice cropland in Jiaxing, Zhejiang, southern China $\left(30^{\circ} 50^{\prime} 7.7^{\prime \prime} \mathrm{N}\right.$, $120^{\circ} 43^{\prime} 5.7^{\prime \prime} \mathrm{E}$ ) in August 2016. Pig manure was obtained from a local commercial pig farm. The properties of the soil and manure are described in Table S1.

The soil was sieved to $<2 \mathrm{~mm}$, and some of the soil was sterilized by $\gamma$-irradiation (35 kGy) (Philippot et al., 2013). The remaining soil was used as an inoculum in a dilution-toextinction experiment. The sterility of the irradiated soil was tested by spreading $0.5 \mathrm{~g}$ onto plates containing tryptic soy broth (TSB) and potato-dextrose agar (PDA) (Yan et al., 2017). No bacterial or fungal growth was observed after six days.

An initial soil suspension was prepared by mixing $30 \mathrm{~g}$ of unsterilized soil with $50 \mathrm{~mL}$ of sterile demineralized water using an ultraviolet-sterilized blender at maximum speed for 5 min (Philippot et al., 2013). Four concentrations of the soil suspension were used as inocula to create a diversity gradient of soil microorganisms ranging from undiluted (D0) to $10^{-2}$ (D1), $10^{-4}$ (D2) and $10^{-8}$ (D3) dilutions, and $5 \mathrm{~mL}$ of each suspension were subsequently inoculated into the $200-\mathrm{mL}$ flasks containing $30 \mathrm{~g}$ of sterilized soil, equivalent to $10^{-1}$, $10^{-3}, 10^{-5}, 10^{-9} \mathrm{~g}$ of inoculum per gram of sterile soil. Positive and negative controls using non-sterile soil (S) and sterile soil (SS), to inoculate the same volume of sterile demineralized water, were also prepared. Each treatment had four repli- 
cates. Each flask received $1.2 \mathrm{~g}$ of pig manure as the source of ARGs (Fig. 1). The flasks were then closed with sterile lids, and the inoculated microcosms were incubated at $20^{\circ} \mathrm{C}$ and at $65 \%$ water-holding capacity by adding sterile demineralized water (van Elsas et al., 2012). Four replicates of each treatment were collected on days $0,10,30,60$ and 90 for the analysis of bacterial abundance and diversity, and the profile of antibiotic resistance.

\subsection{Assessing microbial diversity}

Total DNA was extracted from $0.5 \mathrm{~g}$ of soil for each replicate microcosm from each dilution using a FastDNA ${ }^{\circledR}$ Spin Kit for soil following the supplier's manual (MP Biomedical, Santa Ana, USA). The quality of the DNA was assessed using an ND-1000 spectrophotometer (NanoDrop Technology, Wilmington, USA). The concentration of DNA was determined using a Qubit ${ }^{\mathrm{TM}}$ dsDNA HS Assay kit with a Qubit $^{\mathrm{TM}} 3.0$ fluorometer (Thermo Fisher Scientific Inc, Waltham, USA). Four replicate $50-\mu \mathrm{L}$ PCR reactions were prepared using $1 \mu \mathrm{L}$ each of a forward (515F) and reverse (907R) bar-coded primer (F515: GTGCCAGCMGCCGCGG, R907: CCGTCA ATTCMTTTRAGTTT) (Zhou et al., 2011), $25 \mu \mathrm{L}$ of $2 \times$ ExTaq polymerase (Takara Bio Inc, Otsu, Japan), $1 \mu \mathrm{L}$ of sample DNA as the template and $22 \mu \mathrm{L}$ of nuclease-free PCR-grade water. The PCR program was: $95^{\circ} \mathrm{C}$ for $5 \mathrm{~min}$, followed by 30 cycles of $95^{\circ} \mathrm{C}$ for $30 \mathrm{~s}, 58^{\circ} \mathrm{C}$ for $30 \mathrm{~s}, 72^{\circ} \mathrm{C}$ for $30 \mathrm{~s}$ and a final extension at $72^{\circ} \mathrm{C}$ for $10 \mathrm{~min}$. Negative controls (template DNA replaced with water) were included for detecting any contamination during PCR preparation. PCR products for each sample and replicate were purified using the Wizard SV Gel and PCR Clean-Up System (TIANGEN Biotech, Beijing, China). The purified PCR products were quantified and pooled at the same concentration and then sequenced using an Illumina Hiseq2500 platform (Novogene, Beijing, China).

The quality of downstream analyses was guaranteed by filtering raw pair-end reads to discard raw reads containing three or more ambiguous nucleotides, reads with a low $(<20)$ average quality score, short reads ( $<100 \mathrm{nt}$ ) and barcodes to generate clean joined reads spanning the complete V4-V5 region of the $16 \mathrm{~S}$ rRNA gene. High-quality sequences were processed and analyzed using the QIIME pipeline (Caporaso et al., 2010). Operational taxonomic units (OTUs) were identified using the UCLUST algorithm with a phylotype defined at $97 \%$ sequence similarity (Edgar, 2010). Chimeric sequences, chloroplast and mitochondrial OTUs (around 1\%) and singleton OTUs were discarded from the final OTU data set. The database from the Ribosomal Database Project was used for taxonomic classification (Wang et al., 2007; Cole et al., 2009). Raw sequences were deposited in the National Center for Biotechnology Information (NCBI) Sequence Read Archive (SRA) under accession number SRP108158.

\subsection{Assessing ARGs}

A total of 296 primer sets (Zhu et al., 2017) were used to analyze the soil DNA (Table S2). The primers targeted resistance genes for all major classes of antibiotics (285 primer sets), transposase genes (eight primer sets), the universal class 1 integron-integrase gene (int/1), the clinical class 1 integron-integrase gene (cint/1) and the 16S rRNA gene. All soil DNA was diluted to $50 \mathrm{ng} \cdot \mu \mathrm{L}^{-1}$ using sterile water and amplified in triplicate for each primer set with a Wafergen SmartChip Real-time PCR system in 100-nL reaction volumes. Negative controls without template were

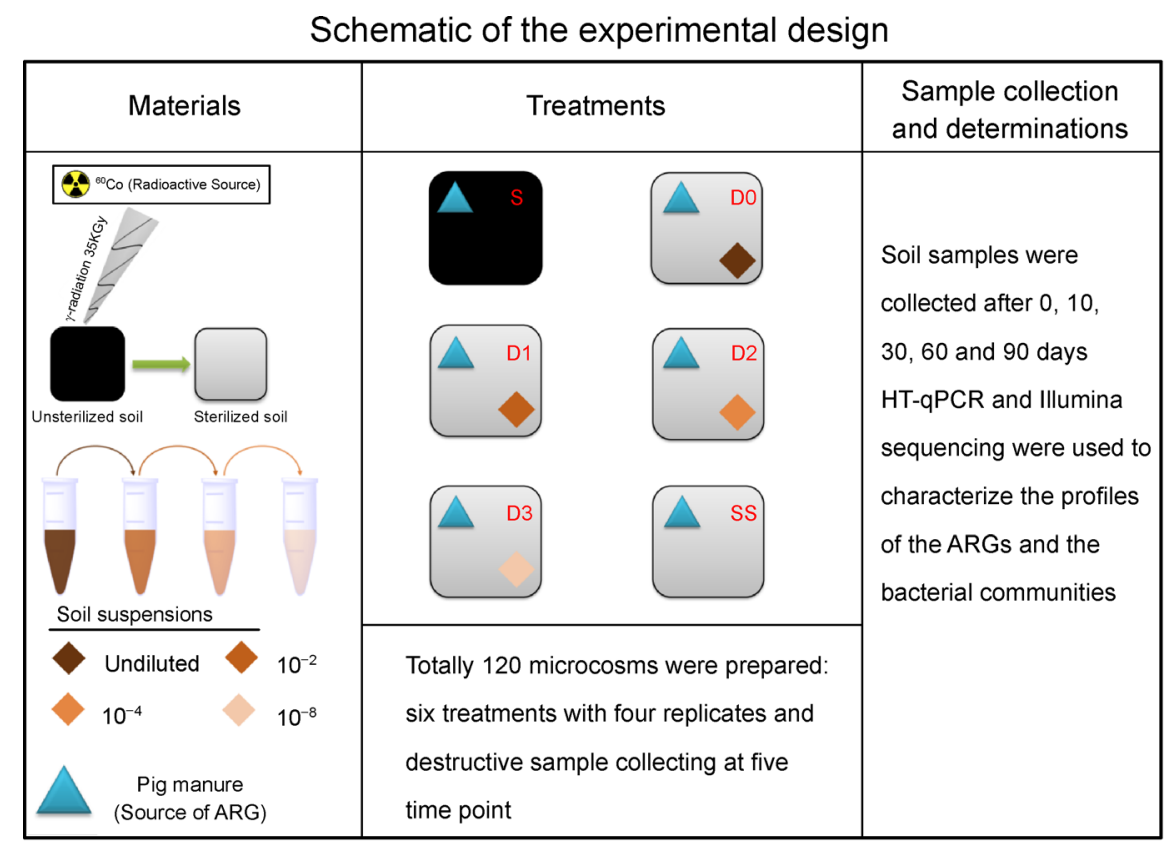

Fig. 1 Schematic of the experimental design. Soil was sterilized by $\gamma$-irradiation, microbial diversity was manipulated using a dilutionreinoculation approach and pig manure was used as the source of ARGs. 
included. A more detailed description of the experimental procedure can be found in a previous study (Chen et al., $2017 \mathrm{~b})$, except we used a threshold cycle $\left(\mathrm{C}_{\mathrm{T}}\right)$ of 29 as the detection limit. The HT-qPCR data were analyzed using the SmartChip qPCR software (V 2.7.0.1). Reactions with poor melting curves and reactions with $<90 \%$ or $>110 \%$ amplification efficiencies were discarded. Retained reactions had both a threshold cycle $<29$ and three positive replicate samples. Relative copy number was calculated as: relative gene copy number $=10^{\left(29-C_{T}\right) /(10 / 3)}$, where $C_{T}$ refers to the results of the quantitative PCR.

Absolute 16S rRNA gene copy numbers were quantified separately using standard curves with a Roche 480 system (Roche Molecular Systems Inc., Branchburg, USA) for determining bacterial abundance. Each $20-\mu \mathrm{L}$ qPCR mixture consisted of $10 \mu \mathrm{L}$ of $2 \times$ LightCycler 480 SYBR Green I Master, $0.5 \mu \mathrm{g} \cdot \mu^{-1}$ bovine serum albumin, $1 \mu \mathrm{M}$ each primer, $5 \mathrm{ng} \cdot \mu \mathrm{L}^{-1}$ template DNA and $6 \mu \mathrm{L}$ of nuclease-free PCRgrade water. The thermal cycling was set the same as for the HT-qPCR. A plasmid control containing a cloned and sequenced $16 \mathrm{~S}$ rRNA gene fragment $\left(1.18 \times 10^{10}\right.$ copies $\cdot \mu \mathrm{L}^{-1}$ ) was used to generate eight-point calibration curves from 10-fold dilutions for standard calculation. All qPCRs were performed in technical triplicates with templatefree negative controls.

\subsection{Statistical analysis}

We used ordinary least squares (OLS) regression models to determine the relationships between the pattern of antibiotic resistance and microbial diversity estimated with OTU richness, diversity and evenness. OLS regression was conducted with R (R Core Team, 2016) and visualized with the "ggplot 2" package (Wickham, 2009). We used structural equation models (SEMs) to evaluate the direct and indirect relationships between dilution, incubation time, bacterial diversity, bacterial abundance, mobile genetic elements (MGEs) abundance and pattern of antibiotic resistance. SEM is an a priori approach able to identify casual relationships between variables by fitting data to the models representing causal hypotheses (Eisenhauer et al., 2015). The first step in SEM analysis thus requires establishing an a priori model based on the known effects and relationships among the drivers affecting antibiotic resistance. The theoretical model assumptions were: (i) dilution and incubation time may directly influence MGE and ARG patterns, (ii) dilution and incubation time may indirectly influence MGE and ARG patterns by affecting bacterial abundance and diversity and (iii) bacterial abundance and diversity may directly influence ARG patterns and may indirectly influence the patterns by affecting MGE abundance and number detected. We determined the distributions of all our variables and tested their normality before modeling. All data were standardized using Z-scores in the downstream analysis. Bivariate correlation determined the pairwise correlations among these variables using SPSS 20 (IBM, Armonk, USA), and the covariance matrix was imported into AMOS 21 (SPSS Inc., Chicago, USA) for SEM construction using maximum-likelihood estimation.

We parameterized our model using our data set and tested its overall goodness of fit. The overall goodness of fit for SEMs does not have a universally accepted test, so we used multiple goodness-of-fit criteria: the chi-square $\left(\chi^{2}\right)$ test (the model has a good fit when $\chi^{2}$ is low and $P$ is high, traditionally $P>0.05$ ), the root mean square error of approximation (RMSEA; the model has a good fit when RMSEA is near 0 ), a high goodness-of-fit index (GFI, traditionally GFI>0.90) and a low Akaike information criterion (from the default model lower than that from saturated and independence models). A reasonable model fit allowed us to interpret the path coefficients of the model and their associated $P$-values. A path coefficient is analogous to a partial correlation coefficient and describes the strength and sign of the relationship between two variables. SEMs can also partition direct and indirect effects that one variable may have on another and estimate the strengths of these multiple effects. We calculated the standardized direct, indirect and total effects of dilution, incubation time, bacterial abundance, bacterial diversity and MGE abundance to aid final interpretation. The net effect of one factor on another was calculated by summing all direct and indirect pathways between the two factors. If the model fitted the data well, the total effect should approximate the bivariate correlation coefficient for that pair of factors.

\section{Results}

\subsection{Microbial community assembly and diversity}

A total of 7251,527 high quality sequences were obtained from all of the samples with sequences per sample ranging from 40962 to 136,022 . The soil microbial community was assembled into 17 phyla (Figure S1A) using the database from the Ribosomal Database Project (Cole et al., 2009). The community was dominated by Actinobacteria, Firmicutes, Proteobacteria, Bacteroidetes, Planctomycetes and Chloroflexi, which are common soil bacterial phyla worldwide (Fierer et al., 2013; Maestre et al., 2015). Firmicutes percentage significantly decreased over time, in contrast to Actinobacteria and Bacteroidetes. It has been reported that the decline of Firmicutes abundance suggested the decrease of manurederived microbiome over time in the soil environment (Gou et al., 2018). The dominant bacterial phyla varied slightly among the dilution treatments. Proteobacteria were nevertheless significantly $(P<0.01)$ enriched after extensive dilution, especially at day 10 after incubation.

Rarefaction curves were constructed for each sample showing the number of operational taxonomic units (OTUs) (Figure S1B), defined at a sequence-similarity cut-off of $97 \%$ in QIIME. Sequencing depths assessed by calculating Good's coverage scores were highly comparable for all samples, ranging from $94.25 \%$ to $98.51 \%$, indicating that the sequen- 
cing depth was adequate to reliably describe the bacterial microbiome. As expected, species richness (observed OTUs) progressively decreased in the dilution treatments (Fig. 2, Figure S2), indicating that the dilution-to-extinction method could effectively manipulate the microbial biodiversity of complex natural ecosystems such as soil (Sun et al., 2015). Species richness also decreased over time. A principal coordinates analysis (PCoA) based on weighted UniFrac distances between samples further indicated that dilution and incubation time significantly shifted the overall profile of bacterial composition (Figure S3). Microbial communities were clustered by their initial dilution levels along PC2, which explained $10.41 \%$ of the total variation, whereas microbial communities were clustered by incubation time along PC1 (explaining $53.55 \%$ of the total variation). This result suggested that time played a more important role than dilution in shaping bacterial composition.

Bacterial abundance was also measured using real-time qPCR for the 16S rRNA gene (Figure S4). Bacterial abundance was higher at the beginning (day 0 ) in treatments $S$ and D0 (because the native microbiota were more abundant), but decreased over time. Bacterial abundance was more stable in D1, D2, D3 and SS (where the native microbiota was less diverse) than $S$ and D0.

\subsection{Resistome assembly and diversity}

HT-qPCR was used to determine the abundance and diversity of ARGs. A total of 195 genes consisting of 186 unique ARGs, the class 1 integron-integrase gene and eight transposase genes were detected (Figure S5). The numbers of ARGs detected in each sample ranged from 47 to 116 with an average of 85 . These ARGs can confer resistance to most of the major classes of antibiotics that are commonly administered to humans and included resistance determinants for aminoglycosides, beta-lactams, Macrolide-LincosamideStreptogramin B (MLSB), multidrug efflux, sulfonamide, tetracycline and vancomycin. The abundance of ARGs ranged from $5.53 \times 10^{10}$ to $1.65 \times 10^{12}$ copies $\cdot g^{-1}$ soil (Fig. 2). ARG abundance was higher in $S$ at the beginning (day 0 ) due to a higher abundance of native antibioticresistant soil microbiota. This observation was consistent with the bacterial abundance (Figure S4). The dilution treatment affected ARG abundance by 10 days after the incubation, with the abundance of ARG increasing as dilution increased (Fig. 2).

3.3 Correlation between the fate of the resistome and microbial diversity

We then used an ordinary least-squares (OLS) regression model to determine the relationship between species diversity and the abundance of ARGs (Fig. 3). Loss of species richness (OTU richness) was linearly associated with an increase in ARG abundance $\left(P=0.0016, R^{2}=0.0810\right)$. The inverse Simpson diversity of OTUs was highly and negatively correlated with the abundance of ARGs $\left(P=0.0003, R^{2}=\right.$ $0.1043)$. In contrast, evenness was not significantly correlated with ARG abundance $\left(P=0.8122, R^{2}=0.0005\right)$. Further analyses provided evidence (Figure S6) that OTU richness was correlated positively with OTU diversity $\left(P<0.0001, R^{2}=\right.$ $0.4264)$ and negatively with OTU evenness $\left(P=0.0064, R^{2}=\right.$ 0.0532).

The OLS regression model indicated that ARG abundance
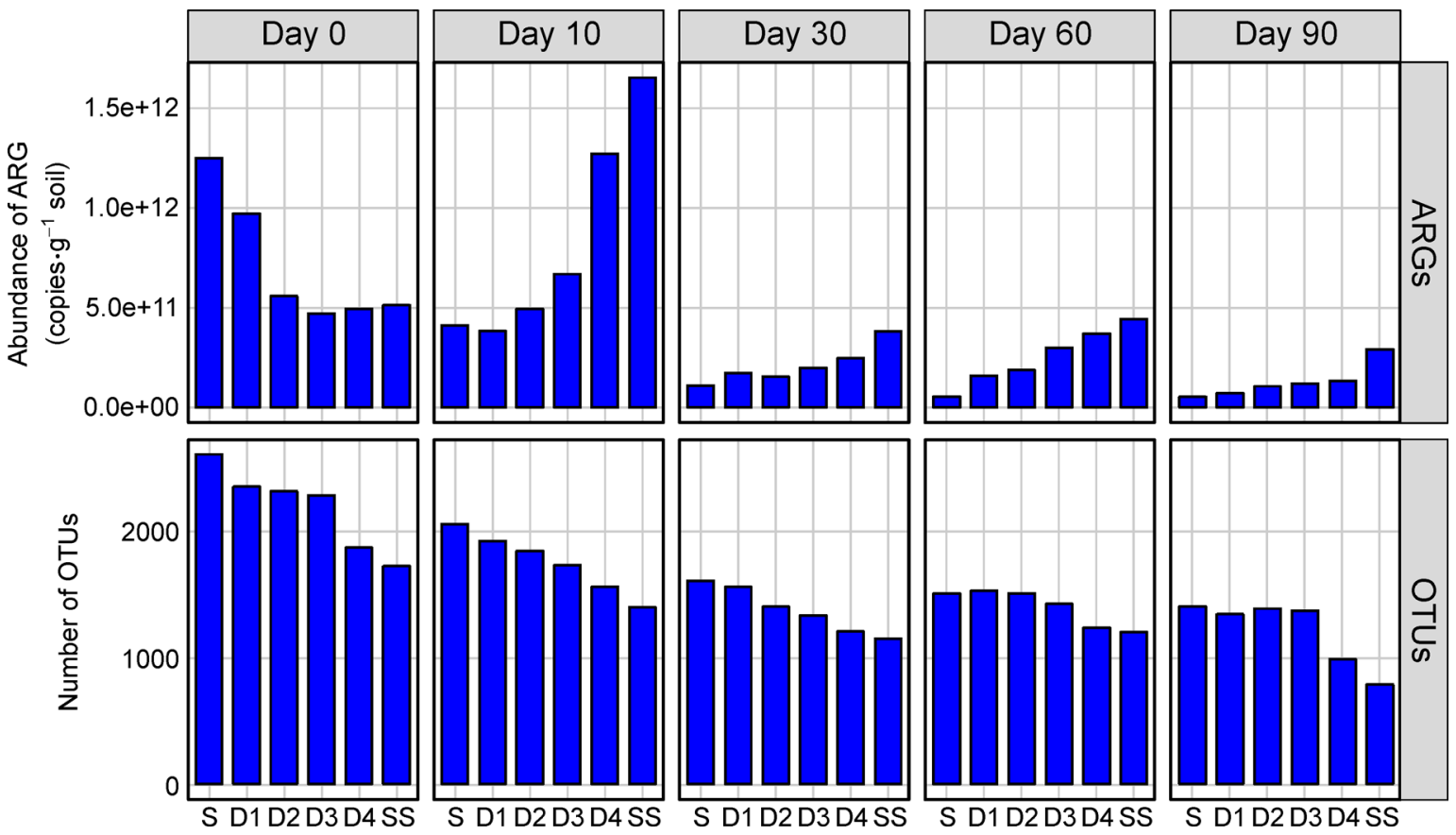

Fig. 2 Abundance of ARGs and number of OTUs associated with the six treatments during the 90-day incubation. OTUs were defined at a 97\% sequence similarity cut-off in QIIME. Bars represent averages of four replicates. 

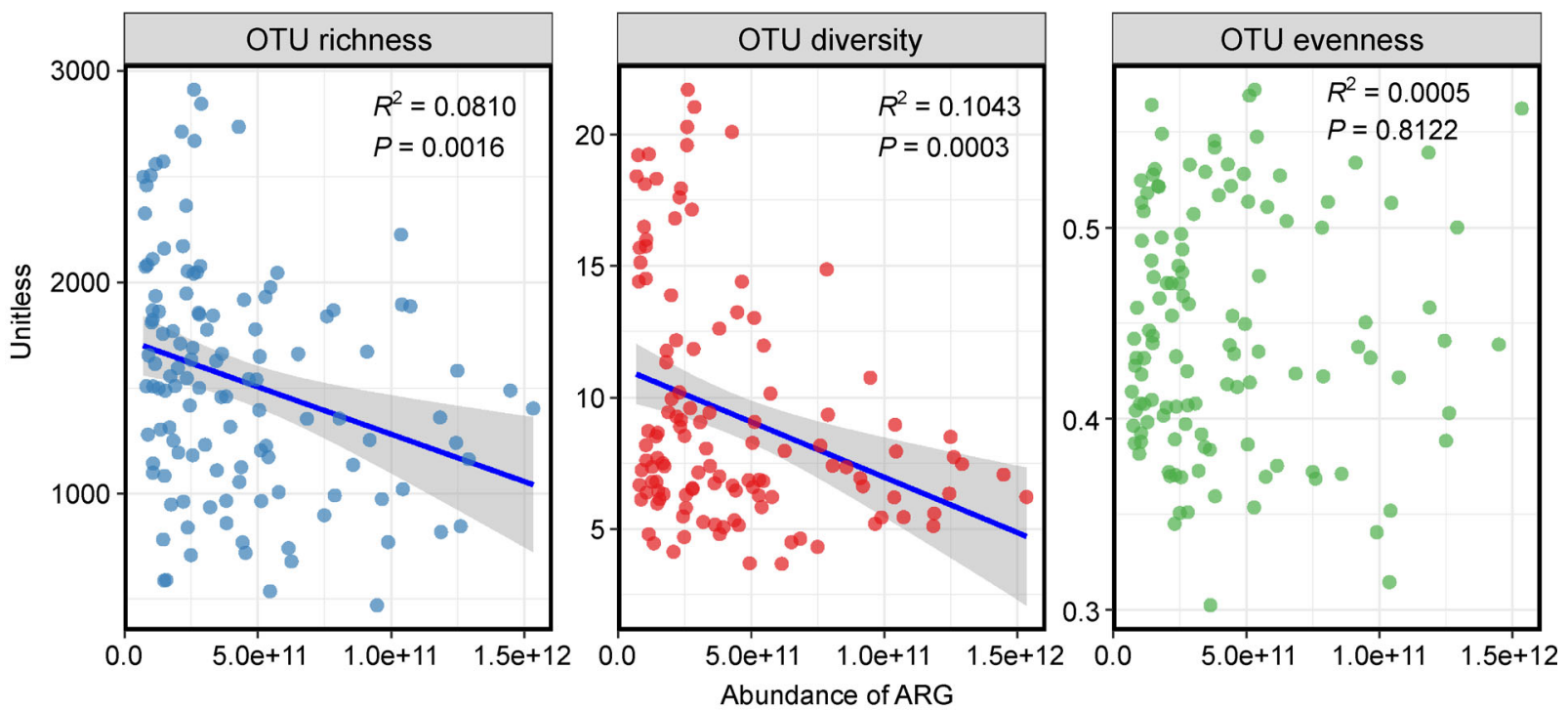

Fig. 3 Ordinary least squares (OLS) regression model showing the relationships of ARG abundance with OTU richness, diversity and evenness. The solid lines indicate significant relationships. The shaded areas show the $95 \%$ confidence interval of the fit.

decreased over time $\left(P<0.0001, R^{2}=0.4065\right)($ Fig. 4). This result indicates that steep increases in ARG abundance following manure application are not maintained in the longterm. We generated SEMs based on known effects and relationships to test whether the relationship between microbial diversity and the fate of ARGs was maintained when accounting for other possible drivers (Fig. 5). The model is an a priori approach that can separate multiple pathways of influence and is useful for exploring the complex networks of

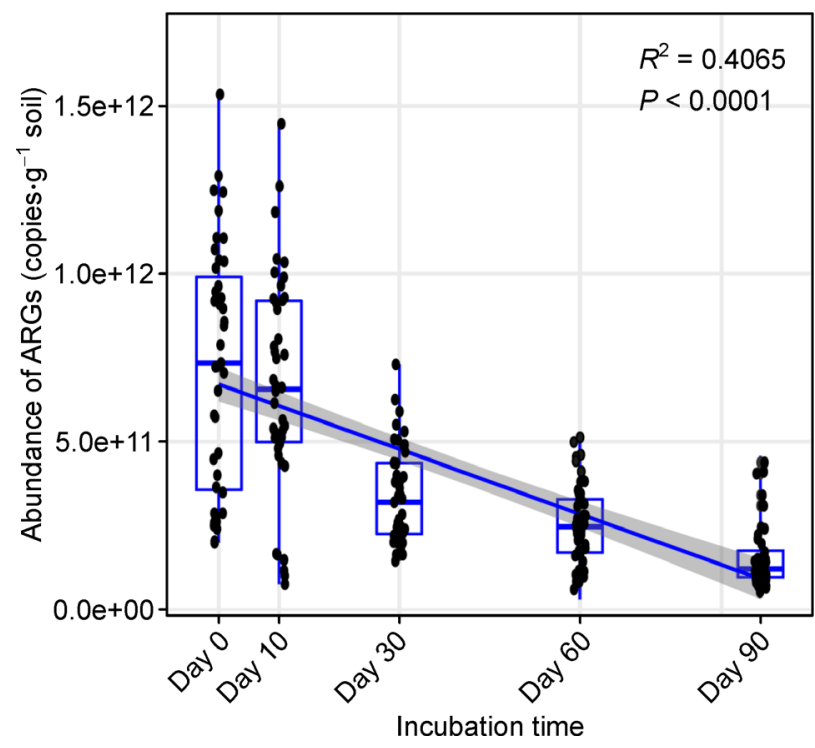

Fig. 4 Relationship between ARG abundance and incubation time. The solid blue line represents the fitted OLS model, and the shaded area shows the $95 \%$ confidence interval of the fit. Box plots show the first $(25 \%)$ and third $(75 \%)$ quartiles, the median and the maximum and minimum values within each data set. relationships in ecosystems (Eisenhauer et al., 2015). Dilution, incubation time and abundance of MGEs and bacteria were included in the model because of their effects on ARG profiles. The model explained $86 \%$ of the variance in ARG patterns. Incubation time and dilution could directly affect the patterns of ARGs or could do so indirectly by strongly affecting the diversity and abundance of bacteria and the abundance of MGEs. Bacterial diversity significantly and directly affected ARG abundance $(\rho=-0.09, P<0.05)$ and indirectly affected the ARG patterns by strongly affecting MGE abundance $(\rho=-0.07, P<0.05)$. Bacterial abundance, though, had nonsignificant direct impacts on ARG abundance $(\rho=0.02, P>0.05)$.

\section{Discussion}

\subsection{Effects of biological barriers on the resistome}

The largest obstacle to understanding the importance of microbial biodiversity for the functioning of ecosystems is the lack of sound experimental methods to induce directed and predictable changes in the diversity of microbial communities in soil (Yan et al., 2015). The present and prior studies (van Elsas et al., 2012; Philippot et al., 2013) have demonstrated that the dilution-to-extinction method could effectively manipulate soil microbial communities to produce a gradient in species richness and diversity (Figs. 2 and S5).

Soil microbial diversity was negatively correlated with ARG abundance, indicating that the loss of microbial diversity could facilitate the proliferation and spread of antibiotic resistance in the soil environment. Our results provide the first empirical genetic evidence that natural ecosystems may be variably resistant to invasion by aliens, and this resistance is associated with the species richness and diversity of the 


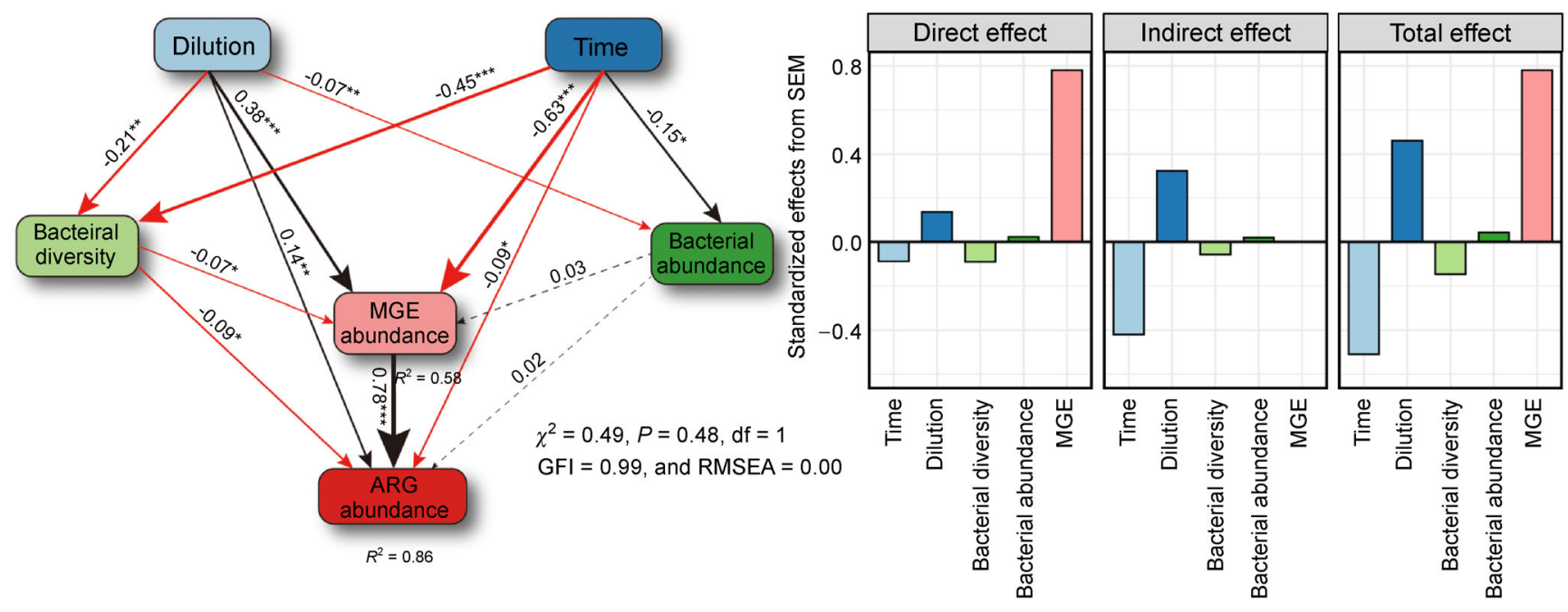

Fig. 5 Structural equation models showing the direct and indirect effects of dilution, time, bacterial abundance, bacterial diversity and MGEs on the ARG patterns. Black and red arrows indicate positive and negative relationships, respectively. Solid and dashed arrows indicate significant and nonsignificant relationships, respectively. Numbers adjacent to the arrows are path coefficients, and the width of the arrows is proportional to the strength of the path coefficients. $R^{2}$ denotes the proportion of variance explained. Significance levels are indicated: ${ }^{*} P<0.05$, ${ }^{* *} P<0.01$ and ${ }^{* *} P<0.001$. Standardized effects (total, direct and indirect effects) are derived from the structural equation models. The hypothetical models fit our data well: $\chi^{2}=0.49, P=0.48, \mathrm{df}=1, \mathrm{GFI}=0.99$ and $\mathrm{RMSEA}=0.00$.

system. Previous studies have suggested that functional redundancy is prevalent in soil microorganisms and may overwhelm any type of relationship between diversity and function, e.g. an initial loss of microbial diversity would not likely substantially affect ecosystem function (Wertz et al., 2007; van Elsas et al., 2012). Functional redundancy, however, may have been overestimated, because the effect of the biological barrier established by microbial diversity was not taken into account.

Our results may be correlative in nature, so are not definitive proof of causation, but they are nevertheless consistent with those from theoretical and experimental studies reporting that highly diverse soil microbial communities can act as a biological barrier against invasion (Case, 1990; Hodgson et al., 2002; Kennedy et al., 2002; Vivant et al., 2013). For example, a recent study found that the survival rate of inoculated Listeria monocytogenes L9 was negatively correlated with inverse Simpson diversity $(\rho=-0.817$, $P<0.05)$ and suggested that the loss of microbial diversity might enhance the circulation of pathogenic microorganisms in soil (Vivant et al., 2013). In addition, our previous study demonstrated that the manure-borne ARGs proliferated more easily in $\gamma$-irradiated soil than natural soil, indicating that indigenous soil microorganisms could prevent the dissemination of ARGs from manure to soil (Chen et al., 2017a). Some manure-borne antibiotic-resistant microbiota may not have been well adapted to the soil environment. The underlying mechanisms may involve resource competition or a negative relationship between native-soil and manure-borne microbiota, which were correlated with the richness and diversity of native soil species. Shifts in conditions from manure to soil may also impede the proliferation of some manure-borne antibiotic-resistant microbiota. We will discuss these possible mechanisms in the following section.

4.2 Possible mechanisms for the effects of biological barriers on the resistome

Competition for nutrients is an important mechanism that may limit invasions in highly diverse communities (Fargione and Tilman, 2005). Resource-based niche theories suggest that the establishment of invading species is dependent on the amount of (limiting) resources not consumed by native species and on the rate at which native and invader species consume resources (Tilman, 1999). Invader species with higher consumption rates may be more efficient in extracting resources and thus more competitive with indigenous species and vice versa. In addition, some bacterial phyla such as Pseudomonads and Actinobacteria can produce ample secondary metabolites (including antibiotics), which play an important role in determining the fate of invading species (Forsberg et al., 2014). For example, van Elsas et al. (2012) found a highly significant negative correlation between invader survival ( $E$. coli strain $\mathrm{T}$ ) and Actinobacteria richness $\left(R^{2}=0.893 ; P=0.0001\right)$, suggesting that Actinobacteria were the major contributor in determining the survival of the invader species in the soil (van Elsas et al., 2012). Furthermore, decreasing the diversity of soil microorganisms would lower the degree of functional overlap and allow invaders to find, conquer and become established in a niche and subsequently persist as part of the community (van Elsas et al., 2007).

Changes in environmental conditions could also affect the 
fate of invader species and genes, which is supported by previous studies reporting that some manure-derived bacteria could not thrive in soil and gradually decreased in abundance after manure treatment, at least partly due to the differences in environmental conditions between soil and the animal gut (Hammesfahr et al., 2008; Heuer et al., 2008; Chee-Sanford et al., 2009). Most of the microbiota from the guts of humans and other animals are restricted to growth under anaerobic conditions (Goodman et al., 2011), which are highly different from the aerobic conditions in our microcosms. Changes in oxygen concentration or $\mathrm{pH}$ would likely affect the fate of manure-borne microbiota in soil. Other mechanisms, e.g. predation and negative species interactions, might also affect the survival of manure-borne species (van Elsas et al., 2012).

\subsection{Implications}

The failure of antibiotic treatments is typically attributed to the "weapon-shield" role that ARGs play in clinical settings (Martínez, 2008), and the pace of development of novel antibiotics is now alarmingly slow (Walsh, 2003). The emergence and spread of antibiotic resistance has now become a global threat to human health (Bush et al., 2011; Pruden et al., 2013). Agricultural use of animal manures is believed to contribute to the spread of antibiotic resistance. The survival in soil of invading manure-borne antibioticresistant bacteria depends strongly on the diversity of soil microorganisms. This soil-borne legacy, however, has long been overlooked. Human activity and climate change have reduced soil microbial diversity in recent decades, which may promote the circulation of ARGs in the environment. Maintaining soil microbial diversity and identifying the driving forces that shape soil microbial diversity are therefore crucial for maintaining the soil-borne legacy.

\section{Conflict of interest}

The authors declare no conflict of interest.

\section{Acknowledgments}

This research was supported by the National Natural Science Foundation of China (21210008, 41571130063), Strategic Priority Research Program of Chinese Academy of Sciences (XDB15020402) and European Research Council from Synergy grant ERC-2013-SyG-610028 “IMBALANCE-P."

\section{Electronic supplementary material}

Supplementary material is available in the online version of this article at http://dx.doi.org/10.1007/s42832-019-0011-0 and is accessible for authorized users.

\section{References}

Allison, S.D., Martiny, J.B.H., 2008. Colloquium paper: resistance, resilience, and redundancy in microbial communities. Proceedings of the National Academy of Sciences of the United States of America 105, 11512-11519.

Bardgett, R.D., van der Putten, W.H., 2014. Belowground biodiversity and ecosystem functioning. Nature 515, 505-511.

Bell, T., Newman, J.A., Silverman, B.W., Turner, S.L., Lilley, A.K., 2005. The contribution of species richness and composition to bacterial services. Nature 436, 1157-1160.

Bush, K., Courvalin, P., Dantas, G., Davies, J., Eisenstein, B., Huovinen, P., Jacoby, G.A., Kishony, R., Kreiswirth, B.N., Kutter, E., Lerner, S.A., Levy, S., Lewis, K., Lomovskaya, O., Miller, J.H., Mobashery, S., Piddock, L.J., Projan, S., Thomas, C.M., Tomasz, A., Tulkens, P.M., Walsh, T.R., Watson, J.D., Witkowski, J., Witte, W., Wright, G., Yeh, P., Zgurskaya, H.I., 2011. Tackling antibiotic resistance. Nature Reviews. Microbiology 9, 894-896.

Caporaso, J.G., Kuczynski, J., Stombaugh, J., Bittinger, K., Bushman, F.D., Costello, E.K., Fierer, N., Peña, A.G., Goodrich, J.K., Gordon, J.I., Huttley, G.A., Kelley, S.T., Knights, D., Koenig, J.E., Ley, R.E., Lozupone, C.A., McDonald, D., Muegge, B.D., Pirrung, M., Reeder, J., Sevinsky, J.R., Turnbaugh, P.J., Walters, W.A., Widmann, J., Yatsunenko, T., Zaneveld, J., Knight, R., 2010. QIIME allows analysis of high-throughput community sequencing data. Nature Methods 7, 335-336.

Cardinale, B.J., Matulich, K.L., Hooper, D.U., Byrnes, J.E., Duffy, E., Gamfeldt, L., Balvanera, P., O'Connor, M.I., Gonzalez, A., 2011. The functional role of producer diversity in ecosystems. American Journal of Botany 98, 572-592.

Case, T.J., 1990. Invasion resistance arises in strongly interacting species-rich model competition communities. Proceedings of the National Academy of Sciences of the United States of America 87, 9610-9614.

Chapin, F.S. 3rd, Zavaleta, E.S., Eviner, V.T., Naylor, R.L., Vitousek, P. M., Reynolds, H.L., Hooper, D.U., Lavorel, S., Sala, O.E., Hobbie, S.E., Mack, M.C., Díaz, S., 2000. Consequences of changing biodiversity. Nature 405, 234-242.

Chee-Sanford, J.C., Mackie, R.I., Koike, S., Krapac, I.G., Lin, Y.F., Yannarell, A.C., Maxwell, S., Aminov, R.I., 2009. Fate and transport of antibiotic residues and antibiotic resistance genes following land application of manure waste. Journal of Environmental Quality 38, 1086-1108.

Chen, Q.L., An, X.L., Li, H., Zhu, Y.G., Su, J.Q., Cui, L., 2017a. Do manure-borne or indigenous soil microorganisms influence the spread of antibiotic resistance genes in manured soil? Soil Biology \& Biochemistry 114, 229-237.

Chen, Q.L., An, X.L., Zhu, Y.G., Su, J.Q., Gillings, M.R., Ye, Z.L., Cui, L., 2017b. Application of struvite alters the antibiotic resistome in soil, rhizosphere, and phyllosphere. Environmental Science \& Technology 51, 8149-8157.

Cole, J.R., Wang, Q., Cardenas, E., Fish, J., Chai, B., Farris, R.J., Kulam-Syed-Mohideen, A.S., McGarrell, D.M., Marsh, T., Garrity, G.M., Tiedje, J.M., 2009. The Ribosomal Database Project: improved alignments and new tools for rRNA analysis. Nucleic Acids Research 37, D141-D145.

DeLong, E.F., Preston, C.M., Mincer, T., Rich, V., Hallam, S.J., Frigaard, N.U., Martinez, A., Sullivan, M.B., Edwards, R., Brito, B. R., Chisholm, S.W., Karl, D.M., 2006. Community genomics 
among stratified microbial assemblages in the ocean's interior. Science 311, 496-503.

Edgar, R.C., 2010. Search and clustering orders of magnitude faster than BLAST. Bioinformatics (Oxford, England) 26, 2460-2461.

Eisenhauer, N., Bowker, M.A., Grace, J.B., Powell, J.R., 2015. From patterns to causal understanding: structural equation modeling (SEM) in soil ecology. Pedobiologia 58, 65-72.

Elton, C., 1958. The ecology of invasions by animals and plants. London: University of Chicago Press. 196pp.

Fargione, J.E., Tilman, D., 2005. Diversity decreases invasion via both sampling and complementarity effects. Ecology Letters 8, 604 611.

Fierer, N., Ladau, J., Clemente, J.C., Leff, J.W., Owens, S.M., Pollard, K.S., Knight, R., Gilbert, J.A., McCulley, R.L., 2013. Reconstructing the microbial diversity and function of pre-agricultural tallgrass prairie soils in the United States. Science 342, 621-624.

Forsberg, K.J., Patel, S., Gibson, M.K., Lauber, C.L., Knight, R., Fierer, N., Dantas, G., 2014. Bacterial phylogeny structures soil resistomes across habitats. Nature 509, 612-616.

Gamfeldt, L., Hillebrand, H., Jonsson, P.R., 2008. Multiple functions increase the importance of biodiversity for overall ecosystem functioning. Ecology 89, 1223-1231.

Gans, J., Wolinsky, M., Dunbar, J., 2005. Computational improvements reveal great bacterial diversity and high metal toxicity in soil. Science 309, 1387-1390.

Goodman, A.L., Kallstrom, G., Faith, J.J., Reyes, A., Moore, A., Dantas, G., Gordon, J.I., 2011. Extensive personal human gut microbiota culture collections characterized and manipulated in gnotobiotic mice. Proceedings of the National Academy of Sciences of the United States of America 108, 6252-6257.

Gou, M., Hu, H.W., Zhang, Y.J., Wang, J.T., Hayden, H., Tang, Y.Q., He, J.Z., 2018. Aerobic composting reduces antibiotic resistance genes in cattle manure and the resistome dissemination in agricultural soils. Science of the Total Environment 612, 1300 1310.

Hammesfahr, U., Heuer, H., Manzke, B., Smalla, K., Thiele-Bruhn, S., 2008. Impact of the antibiotic sulfadiazine and pig manure on the microbial community structure in agricultural soils. Soil Biology \& Biochemistry 40, 1583-1591.

Heuer, H., Focks, A., Lamshoeft, M., Smalla, K., Matthies, M., Spiteller, M., 2008. Fate of sulfadiazine administered to pigs and its quantitative effect on the dynamics of bacterial resistance genes in manure and manured soil. Soil Biology \& Biochemistry 40, 1892 1900.

Hillebrand, H., Matthiessen, B., 2009. Biodiversity in a complex world: consolidation and progress in functional biodiversity research. Ecology Letters 12, 1405-1419.

Hodgson, D.J., Rainey, P.B., Buckling, A., 2002. Mechanisms linking diversity, productivity and invasibility in experimental bacterial communities. Proceedings. Biological Sciences 269, 2277-2283.

Hunt, H.W., Wall, D.H., 2002. Modelling the effects of loss of soil biodiversity on ecosystem function. Global Change Biology 8, 33 50.

Irikiin, Y., Nishiyama, M., Otsuka, S., Senoo, K., 2006. Rhizobacterial community-level, sole carbon source utilization pattern affects the delay in the bacterial wilt of tomato grown in rhizobacterial community model system. Applied Soil Ecology 34, 27-32.

Jung, J., Philippot, L., Park, W., 2016. Metagenomic and functional analyses of the consequences of reduction of bacterial diversity on soil functions and bioremediation in diesel-contaminated microcosms. Scientific Reports 6, 23012.

Kennedy, T.A., Naeem, S., Howe, K.M., Knops, J.M.H., Tilman, D., Reich, P., 2002. Biodiversity as a barrier to ecological invasion. Nature 417, 636-638.

Levine, J.M., 2000. Species diversity and biological invasions: relating local process to community pattern. Science $288,852-854$.

Loreau, M., 2004. Does functional redundancy exist? Oikos 104, 606611.

Mäder, P., Fliessbach, A., Dubois, D., Gunst, L., Fried, P., Niggli, U., 2002. Soil fertility and biodiversity in organic farming. Science 296 , 1694-1697.

Maestre, F.T., Delgado-Baquerizo, M., Jeffries, T.C., Eldridge, D.J., Ochoa, V., Gozalo, B., Quero, J.L., García-Gómez, M., Gallardo, A., Ulrich, W., Bowker, M.A., Arredondo, T., Barraza-Zepeda, C., Bran, D., Florentino, A., Gaitán, J., Gutiérrez, J.R., HuberSannwald, E., Jankju, M., Mau, R.L., Miriti, M., Naseri, K., Ospina, A., Stavi, I., Wang, D., Woods, N.N., Yuan, X., Zaady, E., Singh, B. K., 2015. Increasing aridity reduces soil microbial diversity and abundance in global drylands. Proceedings of the National Academy of Sciences of the United States of America 112, 15684-15689.

Martínez, J.L., 2008. Antibiotics and antibiotic resistance genes in natural environments. Science 321, 365-367.

Matos, A., Kerkhof, L., Garland, J.L., 2005. Effects of microbial community diversity on the survival of Pseudomonas aeruginosa in the wheat rhizosphere. Microbial Ecology 49, 257-264.

Miki, T., Yokokawa, T., Matsui, K., 2013. Biodiversity and multifunctionality in a microbial community: a novel theoretical approach to quantify functional redundancy. Proceedings. Biological Sciences 281, 20132498.

Obernosterer, I., Lami, R., Larcher, M., Batailler, N., Catala, P., Lebaron, P., 2010. Linkage between bacterial carbon processing and the structure of the active bacterial community at a coastal site in the NW Mediterranean Sea. Microbial Ecology 59, 428-435.

Perveen, N., Barot, S., Alvarez, G., Klumpp, K., Martin, R., Rapaport, A., Herfurth, D., Louault, F., Fontaine, S., 2014. Priming effect and microbial diversity in ecosystem functioning and response to global change: a modeling approach using the SYMPHONY model. Global Change Biology 20, 1174-1190.

Peter, H., Beier, S., Bertilsson, S., Lindström, E.S., Langenheder, S., Tranvik, L.J., 2011. Function-specific response to depletion of microbial diversity. ISME Journal 5, 351-361.

Philippot, L., Spor, A., Hénault, C., Bru, D., Bizouard, F., Jones, C.M., Sarr, A., Maron, P.A., 2013. Loss in microbial diversity affects nitrogen cycling in soil. ISME Journal 7, 1609-1619.

Pruden, A., Larsson, D.G., Amézquita, A., Collignon, P., Brandt, K.K., Graham, D.W., Lazorchak, J.M., Suzuki, S., Silley, P., Snape, J.R., Topp, E., Zhang, T., Zhu, Y.G., 2013. Management options for reducing the release of antibiotics and antibiotic resistance genes to the environment. Environmental Health Perspectives 121, 878- 
885.

R Core Team, 2016. A Language and Environment for Statistical Computing; R Foundation for Statistical Computing: Vienna, Austria, http://www.R-project.org.

Reich, P.B., Tilman, D., Isbell, F., Mueller, K., Hobbie, S.E., Flynn, D.F. B., Eisenhauer, N., 2012. Impacts of biodiversity loss escalate through time as redundancy fades. Science 336, 589-592.

Reinthaler, T., Winter, C., Herndl, G.J., 2005. Relationship between bacterioplankton richness, respiration, and production in the Southern North Sea. Applied and Environmental Microbiology 71, 2260-2266.

Ricciardi, A., Maclsaac, H.J., 2008. The ecology of invasions by animals and plants. Nature 452, 34-34.

Singh, B.K., Quince, C., Macdonald, C.A., Khachane, A., Thomas, N., Al-Soud, W.A., Sørensen, S.J., He, Z., White, D., Sinclair, A., Crooks, B., Zhou, J., Campbell, C.D., 2014. Loss of microbial diversity in soils is coincident with reductions in some specialized functions. Environmental Microbiology 16, 2408-2420.

Sogin, M.L., Morrison, H.G., Huber, J.A., Mark Welch, D., Huse, S.M., Neal, P.R., Arrieta, J.M., Herndl, G.J., 2006. Microbial diversity in the deep sea and the underexplored "rare biosphere". Proceedings of the National Academy of Sciences of the United States of America 103, 12115-12120

Su, J.Q., An, X.L., Li, B., Chen, Q.L., Gillings, M.R., Chen, H., Zhang, T., Zhu, Y.G., 2017. Metagenomics of urban sewage identifies an extensively shared antibiotic resistome in China. Microbiome 5, 84.

Sun, M., Ye, M., Wu, J., Feng, Y., Shen, F., Tian, D., Liu, K., Hu, F., Li, H., Jiang, X., Yang, L., Kengara, F.O., 2015. Impact of bioaccessible pyrene on the abundance of antibiotic resistance genes during Sphingobium sp.- and sophorolipid-enhanced bioremediation in soil. Journal of Hazardous Materials 300, 121-128.

Swift, M.J., Andren, O., Brussaard, L., Briones, M., Couteaux, M.M., Ekschmitt, K., Kjoller, A., Loiseau, P., Smith, P., 1998. Global change, soil biodiversity, and nitrogen cycling in terrestrial ecosystems: three case studies. Global Change Biology 4, 729743.

Tilman, D., 1999. The ecological consequences of changes in biodiversity: A search for general principles. Ecology 80, 14551474.

Torsvik, V., Daae, F.L., Sandaa, R.A., Ovreås, L., 1998. Novel techniques for analysing microbial diversity in natural and perturbed environments. Journal of Biotechnology 64, 53-62.

Torsvik, V., Øvreås, L., 2002. Microbial diversity and function in soil: from genes to ecosystems. Current Opinion in Microbiology 5 , 240-245.

van der Heijden, M.G.A., Bardgett, R.D., van Straalen, N.M., 2008. The unseen majority: soil microbes as drivers of plant diversity and productivity in terrestrial ecosystems. Ecology Letters 11, 296310.

van Elsas, J.D., Chiurazzi, M., Mallon, C.A., Elhottova, D., Kristufek, V., Salles, J.F., 2012. Microbial diversity determines the invasion of soil by a bacterial pathogen. Proceedings of the National Academy of Sciences of the United States of America 109, 1159-1164.

van Elsas, J.D., Hill, P., Chronáková, A., Grekova, M., Topalova, Y.,
Elhottová, D., Kristůfek, V., 2007. Survival of genetically marked Escherichia coli 0157:H7 in soil as affected by soil microbial community shifts. ISME Journal 1, 204-214.

Vitousek, P.M., DAntonio, C.M., Loope, L.L., Westbrooks, R., 1996. Biological invasions as global environmental change. American Scientist 84, 468-478.

Vivant, A.L., Garmyn, D., Maron, P.A., Nowak, V., Piveteau, P., 2013. Microbial diversity and structure are drivers of the biological barrier effect against Listeria monocytogenes in soil. PLoS One 8, e76991.

Wagg, C., Bender, S.F., Widmer, F., van der Heijden, M.G., 2014. Soil biodiversity and soil community composition determine ecosystem multifunctionality. Proceedings of the National Academy of Sciences of the United States of America 111, 5266-5270.

Walsh, C., 2003. Where will new antibiotics come from? Nature Reviews. Microbiology 1, 65-70.

Wang, Q., Garrity, G.M., Tiedje, J.M., Cole, J.R., 2007. Naive Bayesian classifier for rapid assignment of rRNA sequences into the new bacterial taxonomy. Applied and Environmental Microbiology 73, 5261-5267.

Wardle, D.A., Bardgett, R.D., Callaway, R.M., Van der Putten, W.H., 2011. Terrestrial ecosystem responses to species gains and losses. Science 332, 1273-1277.

Wardle, D.A., Bardgett, R.D., Klironomos, J.N., Setälä, H., van der Putten, W.H., Wall, D.H., 2004. Ecological linkages between aboveground and belowground biota. Science 304, 1629-1633.

Wertz, S., Degrange, V., Prosser, J.I., Poly, F., Commeaux, C., Freitag, T., Guillaumaud, N., Roux, X.L., 2006. Maintenance of soil functioning following erosion of microbial diversity. Environmental Microbiology 8, 2162-2169.

Wertz, S., Degrange, V., Prosser, J.I., Poly, F., Commeaux, C., Guillaumaud, N., Le Roux, X., 2007. Decline of soil microbial diversity does not influence the resistance and resilience of key soil microbial functional groups following a model disturbance. Environmental Microbiology 9, 2211-2219.

Wickham, H., 2009. ggplot2: Elegant Graphics for Data Analysis. Springer-Verlag New York.

Wright, G.D., 2007. The antibiotic resistome: the nexus of chemical and genetic diversity. Nature Reviews. Microbiology 5, 175-186.

Yan, Y., Kuramae, E.E., de Hollander, M., Klinkhamer, P.G., van Veen, J.A., 2017. Functional traits dominate the diversity-related selection of bacterial communities in the rhizosphere. ISME Journal 11, $56-66$

Yan, Y., Kuramae, E.E., Klinkhamer, P.G., van Veen, J.A., 2015. Revisiting the dilution procedure used to manipulate microbial biodiversity in terrestrial systems. Applied and Environmental Microbiology 81, 4246-4252.

Zhou, J., Wu, L., Deng, Y., Zhi, X., Jiang, Y.H., Tu, Q., Xie, J., Van Nostrand, J.D., He, Z., Yang, Y., 2011. Reproducibility and quantitation of amplicon sequencing-based detection. ISME Journal 5, 1303-1313.

Zhu, Y.G., Gillings, M., Simonet, P., Stekel, D., Banwart, S., Penuelas, J., 2018. Human dissemination of genes and microorganisms in Earth's Critical Zone. Global Change Biology 24, 1488-1499.

Zhu, Y.G., Johnson, T.A., Su, J.Q., Qiao, M., Guo, G.X., Stedtfeld, R. 
D., Hashsham, S.A., Tiedje, J.M., 2013. Diverse and abundant antibiotic resistance genes in Chinese swine farms. Proceedings of the National Academy of Sciences of the United States of America 110, 3435-3440.
Zhu, Y.G., Zhao, Y., Li, B., Huang, C.L., Zhang, S.Y., Yu, S., Chen, Y. S., Zhang, T., Gillings, M.R., Su, J.Q., 2017. Continental-scale pollution of estuaries with antibiotic resistance genes. Nature Microbiology 2, 16270 